\title{
Plant root development: is the classical theory for auxin-regulated root growth false?
}

\author{
Hans G. Edelmann ${ }^{1}$
}

Received: 19 April 2021 / Accepted: 7 August 2021 / Published online: 13 September 2021

(c) The Author(s) 2021

\begin{abstract}
One of the longest standing theories and, therein-based, regulation-model of plant root development, posits the inhibitory action of auxin (IAA, indolylacetic acid) on elongation growth of root cells. This effect, as induced by exogenously supplied IAA, served as the foundation stone for root growth regulation. For decades, auxin ruled the day and only allowed hormonal side players to be somehow involved, or in some way affected. However, this copiously reiterated, apparent cardinal role of auxin only applies in roots immersed in solutions; it vanishes as soon as IAA-supplied roots are not surrounded by liquid. When roots grow in humid air, exogenous IAA has no inhibitory effect on elongation growth of maize roots, regardless of whether it is applied basipetally from the top of the root or to the entire residual seedling immersed in IAA solution. Nevertheless, such treatment leads to pronounced root-borne ethylene emission and lateral rooting, illustrating and confirming thereby induced auxin presence and its effect on the root - yet, not on root cell elongation. Based on these findings, a new root growth regulatory model is proposed. In this model, it is not IAA, but IAA-triggered ethylene which plays the cardinal regulatory role - taking effect, or not - depending on the external circumstances. In this model, in water- or solutionincubated roots, IAA-dependent ethylene acts due to its accumulation within the root proper by inhibited/restrained diffusion into the liquid phase. In roots exposed to moist air or gas, there is no effect on cell elongation, since IAA-triggered ethylene diffuses out of the root without an impact on growth.
\end{abstract}

Keywords Auxin (IAA) · Root development $\cdot$ Root growth $\cdot$ Ethylene $\cdot$ Gravitropism $\cdot$ Auxin gradient $\cdot$ Lateral root . Gravitropic growth $\cdot$ Soil compaction $\cdot$ Plant signal transduction

\section{Introduction}

Based on the early experiments with coleoptiles of Avena sativa carried out by Paâl (1919) and Went (1926), the existence of "growth accelerating substances" had been postulated early last century (Went 1926; Went and Thimann 1937). The by then unidentified substance ("Wuchsstoff"), diffusible from the coleoptile tips into agar blocks, was according to literature - soon independently identified by Went and Thimann, and named after the Greek auxein - to grow, as "auxin" (Kögl et al. 1934a, b; Went 1926; Thimann 1935). During the following decades, the relevance of auxin

Handling Editor: Peter Nick

Hans G. Edelmann

h.edelmann@uni-koeln.de

1 Institut für Biologiedidaktik, Universität zu Köln, Cologne, Germany
(IAA, indolyl-3-acetic acid) was increasingly recognised as a chemical messenger in plants ("growth substance"), relevant for a multitude of diverse physiological processes (Davies 1995; Lv et al. 2019).

Over time, other plant hormones with diverse competences have been and are still being discovered (Kleine-Vehn and Sauer 2017); in addition to what has been thought for many years, namely that plant development is regulated by a total of five hormone groups, namely auxins, gibberellins, cytokinins, abscisic acid and ethylene.

With respect to auxin, besides a broad range of multiple other research aspects, such as the apical dominance in plant shoots (Cline 1997; Kebrom 2017), or the problem of auxin transport (Gälweiler et al. 1998; Friml et al. 2002), a vast number of the investigations dealt with the principle mode of its molecular causal action responsible for cell (wall) extension in shoot parts (Cleland 1970; Edelmann et al. 1989; Kutschera 2006; Kutschera and Khanna 2020). 
An early hypothesis was put forward by Hager et al. (1971, 1991), the so-called acid-growth hypothesis, leading to a longstanding debate, mainly driven by Kutschera and Schopfer (1985) and Cleland (Rayle and Cleland 1992). Despite the lack of detail still being unresolved and the still ongoing debate, the controversial discussions have nevertheless greatly contributed to the understanding of IAA-mediated cell wall bound processes in the context of cell expansion (Arsuffi and Braybrook 2018). Edelmann and Schopfer (1989) demonstrated the strict short-term interdependence between protein synthesis and cell expansion in segments of maize coleoptiles, which is inhibited within a few minutes after inhibition of protein synthesis. In contrast, even inhibition of cellulose synthesis lasting many hours has no impact on auxin-induced cell elongation (Edelmann and Schopfer 1989; Edelmann et al. 1989, 1995). With respect to the causal relevance of wall acidification in the mechanism of cell wall expansion, Cosgrove's group eventually discovered in the 1990s the so-called expansins (McQueen-Mason et al. 1992; Cosgrove 2000). Expansins are wall proteins that are thought to mediate acid-induced growth by catalysing cell wall extension without disrupting wall polymers. Current understanding attributes expansins to a wall loosening effect without disrupting covalent bonds but rather by decreasing hydrogen bond interactions between wall polymers (Darley et al. 2001). These proteins have been thoroughly and extensively studied and have been demonstrated also to occur, at least as derivatives, in bacteria (Cosgrove 2015).

In contrast to the enhancing effect of IAA on cell expansion in upper plant organs, elongation growth of root cells is - according to the text-book - inhibited at similar concentrations (Thimann 1969). Few studies have dealt with this apparent contradiction, although effects of auxin on ethylene synthesis were demonstrated relatively early (Andreae et al. 1968; Chadwick and Burg 1970), suggesting IAA-induced inhibition of root elongation to be mediated by ethylene. Yet, other studies decisively declared IAA-induced growth inhibition of root cells not to be mediated by ethylene but by auxin itself (Eliasson et al. 1989).

Although the number of studies indicating some coherence of IAA and ethylene - and vice versa - increased (Alarcon et al. 2014), the general methodological approach of research ultimately deemed IAA the primary regulatory role of inhibition of root growth (Overvoorde et al. 2010). It is therefore not surprising, and to some extent plausible that the differential growth of graviresponding plant organs is considered as the result of a redistribution of IAA between the flanks of the organs. In graviresponding roots this results in inhibition of growth of the lower organ flank by accumulation of IAA (in contrast to graviresponding shoots, thereby accelerating growth).

The auxin (redistribution) model, generally being applied to both shoot and root growth regulation, was "not to be shaken", although studies demonstrated that maize coleoptiles incubated in IAA solutions still reacted gravitropically. Despite a general growth-enhancing effect of the exogenous IAA, such treated organs exhibited pronounced differential growth of opposite organ flanks (Edelmann 2001). Already by then, the broadly ignored observation implied a regulation mechanism for differential cell extension independent of, or at least not based on, a gradient of IAA.

Regardless of these critical findings, the classic model has nevertheless been apparently substantiated and supported by molecular biology studies, using special markers/reporters, aimed at visualising the gravistimulated redistribution of auxin as the basic principle for differential gravitropic root growth (Ottenschläger et al. 2003a, b). For a review, also see $\mathrm{Su}$ et al. (2017).

From the very beginnings until nowadays, the applied experimental approach for these investigations in root growth regulation and its dependence on IAA concentration consisted for the majority of studies in incubating roots in adequate IAA solutions of different concentrations, but also by growing roots attached to vertical agar plates supplied with Murashige Skoog medium (e.g. French et al 2009). By measuring their effect on root elongation growth, as compared to water controls, the observed effects were assigned to the effect of the substance applied (e.g. Evans et al. 1980). By detecting differences in parameters or processes between the different treatments, potentially causal steps, or at least ones relevant for the mechanism of IAA-regulated cell extension growth - or inhibition of cell extension - were, and are, aimed to be elucidated (Young et al. 1990).

The logic of the present study is based on a similar principle approach: recognising differences in the dependency of the different treatments, or methodological impacts, and working out the coherent regulatory implications. Similar to the rationale of a previous study (Edelmann 2018), the validity of IAA-regulated root growth was put to the test - by comparison of differences in root behaviour in the presence of IAA as compared to water controls. Moreover, root growth was analysed during incubation in solutions of IAA as well as under conditions of exogenous IAA supply, yet with roots exposed to humid gas phase.

\section{Materials and methods}

Maize kernels (Hybridmais, Ronaldinio, KWS) were germinated in darkness at room temperature $\left(\sim 21-23^{\circ} \mathrm{C}\right)$ by rolling them in moistened sheets of filter paper (MN 710; $580 \times 580 \mathrm{~mm}$ ). To get straight roots, 20 kernels were placed in rows at distances of $1-1.5 \mathrm{~cm}$ on chromatography paper sheets $(40 \times 10 \mathrm{~cm})$. The rolled sheets were then placed vertically in $200-\mathrm{mL}$ glass beakers, and filled with distilled water to a depth of $1 \mathrm{~cm}$. The beakers were then loosely covered 
with aluminium foil. After 2-3 days, the germinated seedlings with developed coleoptiles and roots with lengths in the range of 2 to $2.5 \mathrm{~cm}$ were selected for the experiments (for details, also see Hahn et al. 2006).

For measurement of root growth in liquids, seedlings were fixed between 5-mm lattice windows made of foamed material, which floated on the surface of suitable solutions in glass beakers with a volume of $300 \mathrm{ml}$, so that the roots could grow vertically downwards and shoot parts, in air, could grow upwards. The solutions were slightly aerated with air by means of a pump via silicone tubes with injection needles attached to the ends. Root growth in humid air was achieved by placing the cores of the seedlings between layers of heavily soaked soft filter paper so that the core absorbs the liquid and releases the volume of liquid to the roots and the shoot parts, i.e. the coleoptile with the primary leaf enclosed.

Graviresponding root growth was measured by two different treatments: (a) placing 2-day-old seedlings on waterimbibed filter paper on top of Styrofoam stands within PET containers ("Gerda-Dosen") with the root horizontally free into the gas space; the container bottoms of the lidded containers were covered with water-soaked filter paper to ensure water-saturated air conditions; (b) incubation of horizontally placed roots of intact seedlings in diverse solutions in special growth chambers which allowed roots to be incubated in solutions and the rest of the seedling growing in moist air, sealing the root/shoot region with "Fitnis SH medium" (Kaniedenta), monitoring their gravitropic growth behaviour dependence on IAA concentration over time.

To measure ethylene emission from air-exposed roots as induced by exogenously supplied IAA, 3-day-old maize seedlings were incubated upside down with the grain and shoot part immersed in auxin solution in batches of 35 seedlings in glass containers and the ethylene emission determined. Ethylene was analysed with an "ETD 300" ("Sensor Sense"). Depending on head space and seedling numbers, the flow rates (stop and flow operation mode) were adjusted to an average of $1 \mathrm{~L} \mathrm{~h}^{-1}$, as described previously (Dreyer and Edelmann 2018).

\section{Results}

As demonstrated in numerous previous studies (Thimann 1936; Edwards and Scott 1977; Evans and Cleland 2008), incubation of maize roots of intact seedlings in solutions of IAA results in a concentration-dependent inhibition of root elongation growth (Fig. 1). On average, above a concentration higher than $10^{-10} \mathrm{M}$ IAA elongation growth is significantly inhibited, eventually ceasing at a concentration of $10^{-5} \mathrm{M}$. As shown, there is no strict linear relation between IAA concentration and inhibition of growth, but

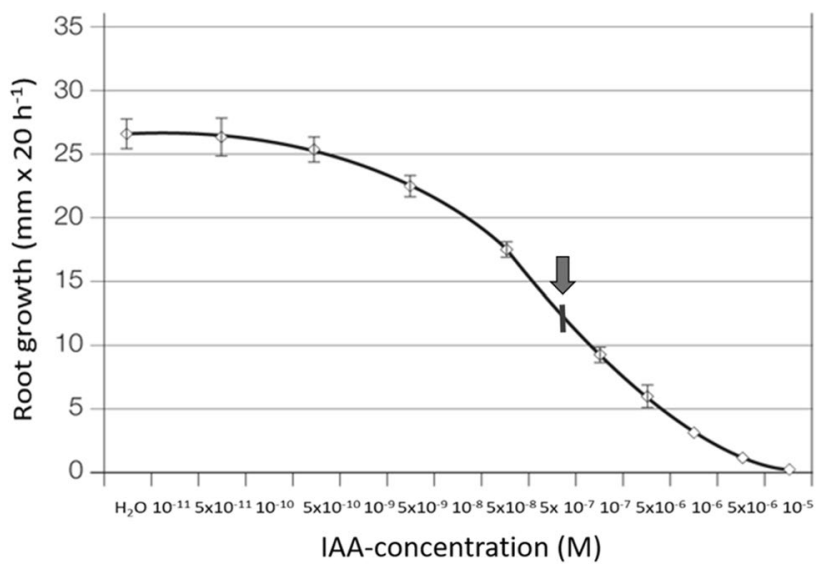

Fig. 1 Effect of exogenous IAA (indolylacetic acid) on elongation growth of roots incubated in adequate solutions in concentrations $(\mathrm{M} / \mathrm{L})$ as indicated (values based on $n=30 \pm \mathrm{SD}$ ). The vertical arrow and crossing bar indicate the IC50 value

rather a sigmoidal curve, which is from a biochemical perspective, potentially indicative for some kind of cooperative mechanism. The IC50 value corresponds to a concentration of $5 \times 10^{-5}$ M IAA.

The inhibiting effect on root elongation is at higher IAA concentrations, i.e. $10^{-5} \mathrm{M}$, but also $10^{-6} \mathrm{M}$, macroscopically characterised by root swelling (Fig. 2). This effect is accompanied by inhibited cell elongation and an increase in the cell circumference of the cells within the elongation zone of the root (Fig. 3), which is reminiscent of an effect that has been shown many times for the effect of ethylene.

In contrast to these "classical observations", this supposedly typical, root-specific IAA effect was not observed when the roots were incubated in IAA-imbibed filter paper - apart from the very first few millimetres of the tip. Such growth conditions were achieved by placing and wrapping the seedlings including parts of the upper root in solutionimbibed filter paper on top of small Styrofoam pedestals, the root-tip sections of which were allowed to grow into the water vapour-saturated air space (Fig. 4). In fact, such roots did not differ from adequate water controls, neither with respect to root elongation, nor the gravicurvature angle of the roots, obtained within a stimulation period of $20 \mathrm{~h}$.

This unexpected finding animated clarification of how gravistimulated growth is affected in horizontally gravistimulated roots, incubated in solutions of IAA. In order to observe any growth (which is inhibited in solutions of $10^{-5} \mathrm{M}$ IAA), we chose a concentration of $10^{-6} \mathrm{M}$ IAA, which has been shown to inhibit root elongation growth by on average $87 \%$ (Fig. 1). In doing so, it turned out that roots exhibited during a period of 30 -h gravitropic growth (data not shown), despite a general growth inhibition by on average $85 \%$ and several fold faint swelling of the roots (similar to the effect shown in Fig. 2). This effect is reminiscent of 


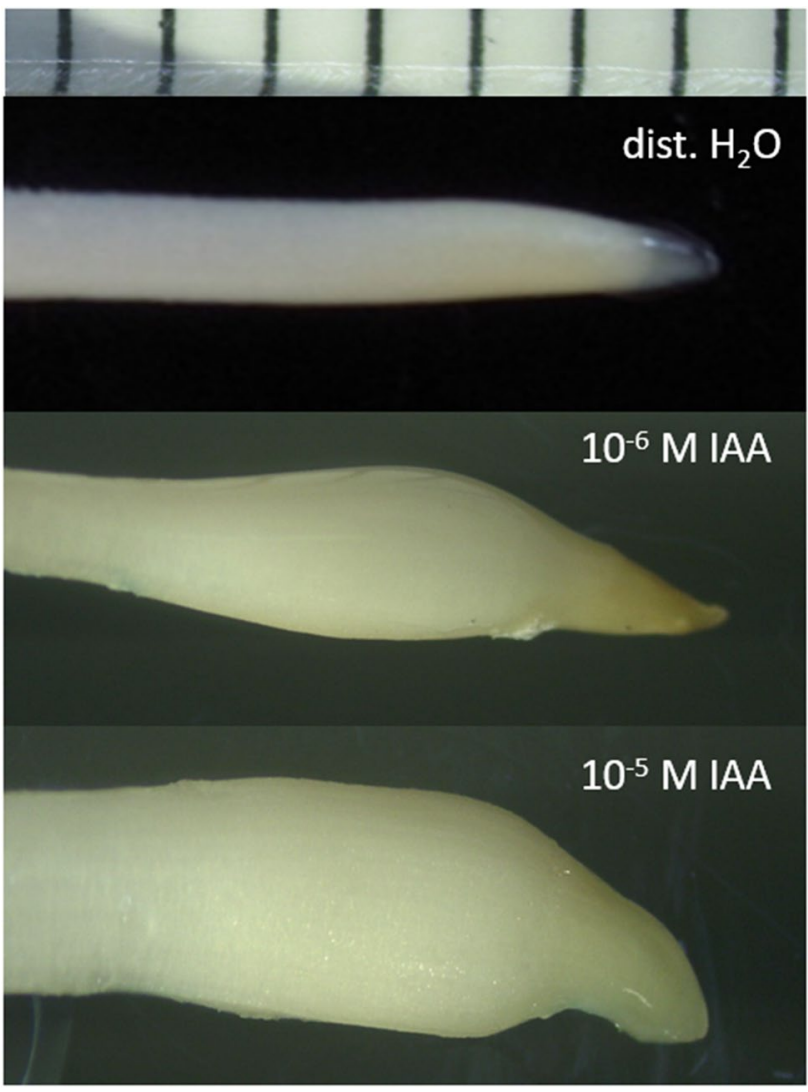

Fig. 2 Typical images of maize root tip regions of intact seedlings incubated for $20 \mathrm{~h}$ in either distilled water, $10^{-6} \mathrm{M}$ or $10^{-5} \mathrm{M}$ IAA solution; the upper bar shows millimeteer distances earlier studies in coleoptiles, in which coleoptiles of maize gravistimulated in solutions of IAA exhibited pronounced gravitropic growth, despite a - in this case - pronounced general growth stimulation (Edelmann 2001).

The inhibiting effect of IAA on root elongation growth was only observed in roots incubated in solutions - but not in air-grown roots supplied with solutions of IAA (Figs. 1 and 4). An interesting question therefore seemed to be how a (re)immersion of previously air-grown, water- and IAA solution-supplied roots affects growth. The intention was to investigate and substantiate whether the root incubation conditions determine the effect of IAA - even after an airgrowing phase of the very same roots.

In order to grow the very same, previously in air-grown roots in liquid, we let tips of air-grown roots of seedlings placed on small pedestals and imbibed in filter paper - both water or IAA supplied - grow into solution-imbibed filter paper (Fig. 5). It turned out that growth of air-exposed roots that were supplied with water via the shoot and the upper root area and subsequent water reimbibition was little or not impaired in comparison with air-grown roots (Fig. 5). In contrast to this, the growth of seedlings which grew with $10^{-5} \mathrm{M}$ IAA over the shoot and the upper root parts and their roots in the air and then grew into water-soaked filter paper was strongly inhibited. It is therefore the incubation conditions of the roots revealing the IAA-dependant impact, which did not come to effect (Fig. 4) as long as they were not immersed in liquid phase, despite being delivered with IAA from the IAA-imbibed upper root part and residual seedling. Although this growth inhibition is an indirect proof of the
Fig. 3 Cell length and cell diameter (upper half of the picture), as well as light microscopical images (100-fold magnification) of longitudinal sections of fixed, Eosinstained roots of intact maize seedlings incubated for $20 \mathrm{~h}$ in $10^{-6} \mathrm{M}$ IAA (left bottom picture) and $\mathrm{H}_{2} \mathrm{O}$ (right bottom picture), taken from the area of $3 \mathrm{~mm}$ behind the quiescent centre. Mean values $( \pm$ S.E.; $n=18-24)$. Vertical bars represent $100 \mu \mathrm{m}$
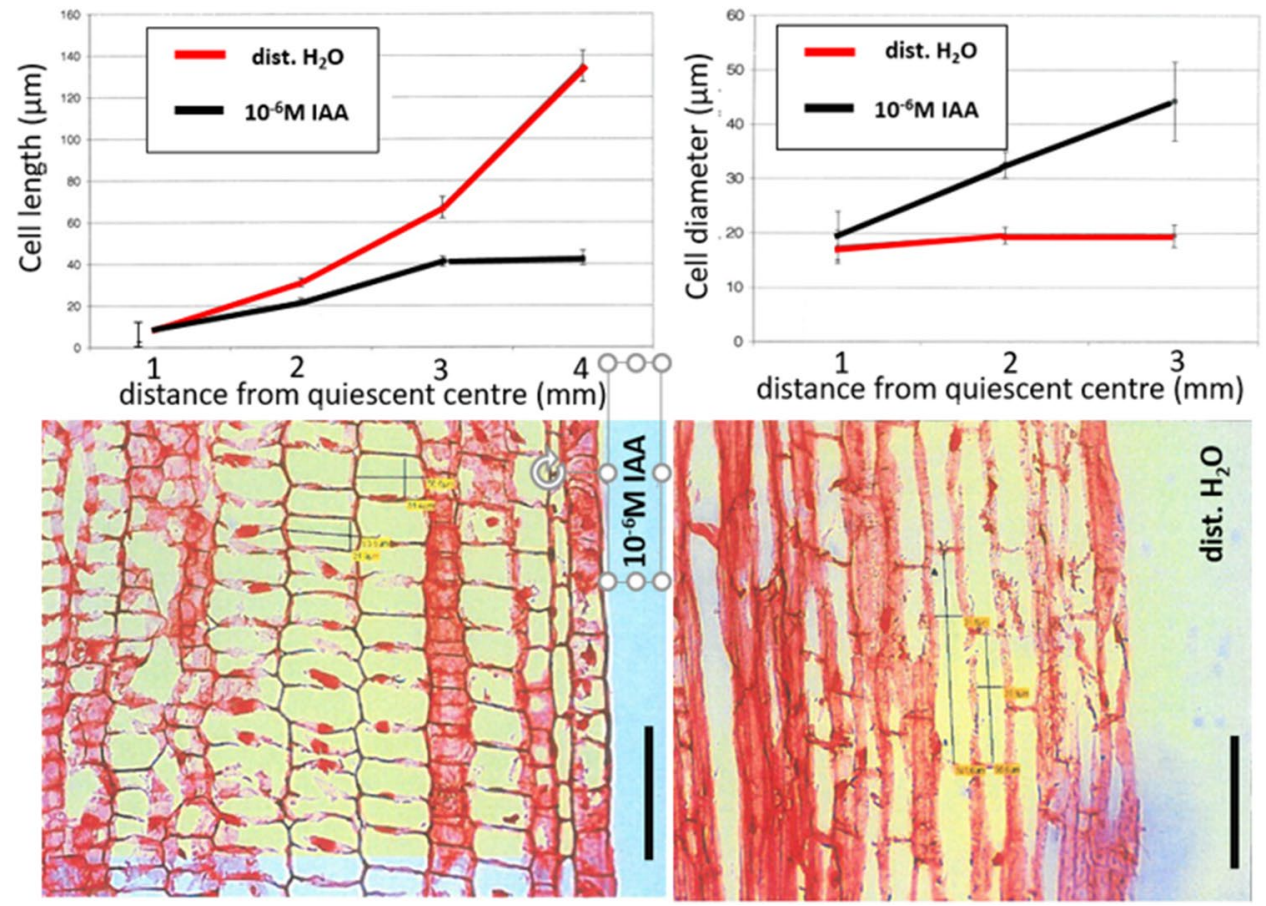


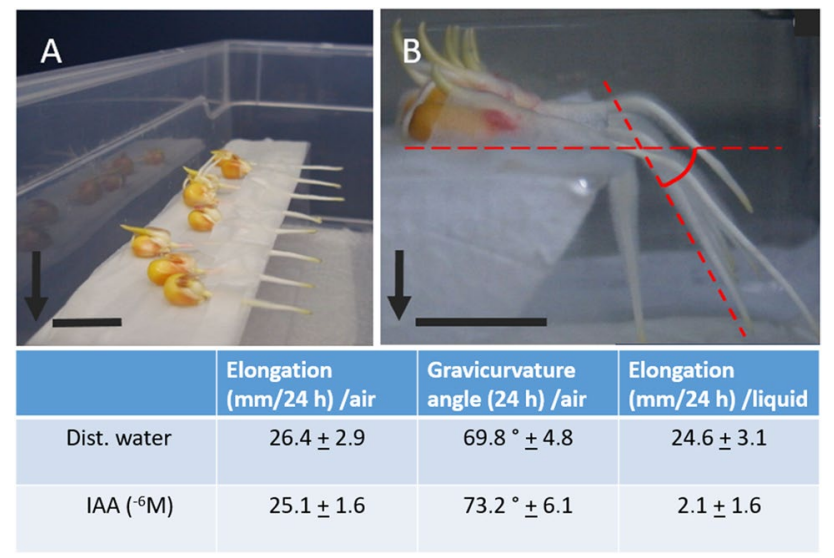

Fig. 4 Images of the methodical procedural steps for elongation growth/gravistimulation experiments; (A) Three-day-old maize seedlings horizontally placed on Styrofoam bases, covered with water- or IAA solution-imbibed filter paper in water vapour-saturated plastic boxes at time $=0 ;(\mathbf{B})$ Typical graviresponses of the seedling roots after $24 \mathrm{~h}$ of gravistimulation. Seedlings placed on Styrofoam pedestals (with partial coverage of base parts of the roots); elongation of air exposed roots (air), gravicurvature of roots exposed to air (air), and elongation of roots incubated in solutionimbibed filter paper (liquid). Arrows indicate the gravivector; horizontal bars represent 1-cm length. Mean values $( \pm$ S.E.; $n=24)$

presence of IAA in the root tip of seedlings which are exogenously supplied with IAA via the shoot and the upper section of the root, the absence of growth inhibition in water supplied, similarly reimmersed roots, represents strong evidence for its presence within the cells of the root tip. Although this would be diametrically opposed to any IAA transport model of recent decades (Davies 1995), it could in principle be argued that the root of the seedlings incubated in soaked filter paper, which are only supplied with IAA from the shoot and grain area, is not effectively supplied with IAA within the root proper. Evidence against such reasoning is shown in Fig. 6, where air-grown roots of water-supplied seedlings are compared to IAA-supplied roots. As already shown in many papers on the effect of ethylene (Alarcon et al. 2014), IAA causes pronounced lateral root formation (Fig. 6), which is not observed in the water control during the observed $72 \mathrm{~h}$.
In a previous study in maize roots, it was shown that the more strongly ethylene synthesis was inhibited, the less pronounced the gravireaction was (Edelmann and Roth 2006). This earlier finding motivated us to test the extent to which exogenously supplied IAA induces ethylene synthesis in roots, since the IAA effects, as measured during incubation of roots in solutions reported in this study, strongly resemble ethylene effects frequently reported (Woods et al 1984; Solano and Ecker1998; Aloni 2021).

As shown in Fig. 7, roots of seedlings exogenously supplied with IAA via the shoot/kernel part exhibited a strong increase in emitted ethylene above a concentration of $10^{-6} \mathrm{M}$ IAA over time. The original, seemingly linear correlation on dependence of the concentration of applied IAA during the first $3 \mathrm{~h}$ after application changed over time, with strong ethylene increases within the $5 \times 10^{-5}$ M IAA treatment.

Also this effect demonstrates that IAA induces ethylene synthesis in roots, which was earlier shown to be crucial for its gravireaction (Edelmann and Roth 2006). Due to its solubility properties in water, under liquid incubation conditions, ethylene inevitably accumulates, which can thus exert its effect within the roots, but not so in air-exposed treatments where ethylene escapes (Fig. 7). In addition, it is known that ethylene has in water a diffusion coefficient that is 10,000 times lower than that in air (Jackson 1985; Abeles et al. 1992, Bleeker and Kende 2000). Ethylene is therefore substantially retained within the root proper during conditions of incubation in liquid. In contrast, in roots exposed in air, ethylene is not retained but to a certain extent volatilised.

\section{Discussion}

Without any doubt auxin plays an important and crucial role in plant development, in concert with a range of various other hormones so far identified (Srivastava 2002; Kieffer et al. 2010). Concerning its role in root development, it has been reported early on since the thirties of last century to inhibit root elongation growth (Nielsen 1930; Thimann 1936). This inhibiting effect - as observed in solutionincubated roots - has since set the research framework and the research strategy for the majority of subsequent studies.
Fig. 5 "Bridge Experiment", in which roots of intact seedlings were supplied with liquid (water or IAA solution), grown for $8 \mathrm{~h}$ in moist air and then reimmersed in filter paper for following $24 \mathrm{~h}$ imbibed either with water or IAA solution. Mean values ( \pm S.E.; $n=24$ )

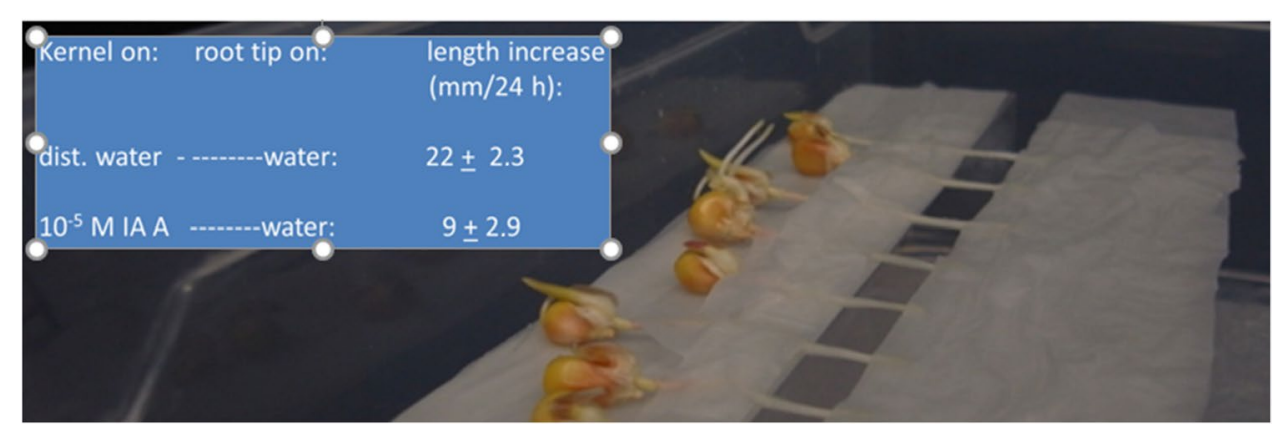




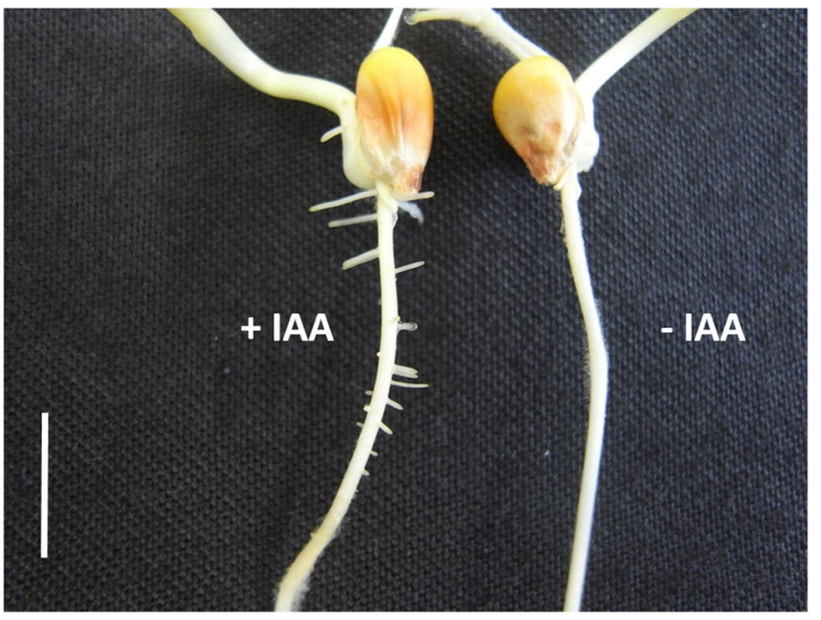

Fig. 6 Typical images of roots of intact seedlings grown for $72 \mathrm{~h}$ in moist air and delivered from the shoot part with IAA solution (left hand, +IAA) or dist water (right hand,-IAA). The bar represents 1 -cm length

In fact, it is this key observation that has been repeatedly demonstrated in countless studies dealing with IAAregulated root growth - it established the basis for a model on root growth regulation that has dominated research for the last hundred years (Overvoorde et al. 2010). This effect is - once more - demonstrated in Fig. 1 in this present study. It illustrates the concentration dependence of elongation growth of roots incubated in an array of solutions of IAA and distilled water.
The apparently unequivocal exogenously inducible effects of IAA, in shoots in the form of induction of cell extension growth and in roots in the form of inhibition of cell extension (Evans and Cleland 2008) soon led to two distinct main research landscapes, being characterised by different aspects of research interests (Kutschera and Schopfer 1985; Kutschera 2006; Gälweiler et al. 1998; Friml et al 2002). For long, a central problem in above ground organs consisted in the IAA-induced wall-loosening scenario, within which so-called expansins seem to play a relevant role (Cosgrove 2015). In roots, its opposing effect, namely suppression of cell extension growth, was not pursued in as much detail. The inhibiting effect on root growth by IAA mainly served to address the question of which proteins, depending on which mechanisms, accomplish IAA transport. This question has been studied particularly in dependence of gravity - not focusing on the question of the nature of inhibition of root cell growth (Young et al. 1990; Ottenschläger et al. 2003a, b). In addition to the manyfold demonstrated inhibiting effects of IAA-incubated roots, it has been shown that graviresponding roots are generally characterised by growth inhibition of the lower organ flank (Firn and Digby 1980). Therefore, most research activity during early, but also recent, years was devoted to the question of how gravitropic root growth is regulated by redistribution of the growth-inhibiting auxin - essentially ignoring other potential candidates or alternative scenarios (Friml et al. 2002). One of the crucial problems was the mechanism of the "inverse fountain model" of transport of IAA originating
Fig. 7 Ethylene emission from roots of 3-day-old maize seedlings incubated upside down in diverse incubation solutions/ dist. water, during a measuring period of $14 \mathrm{~h}$, employing the flow modulus

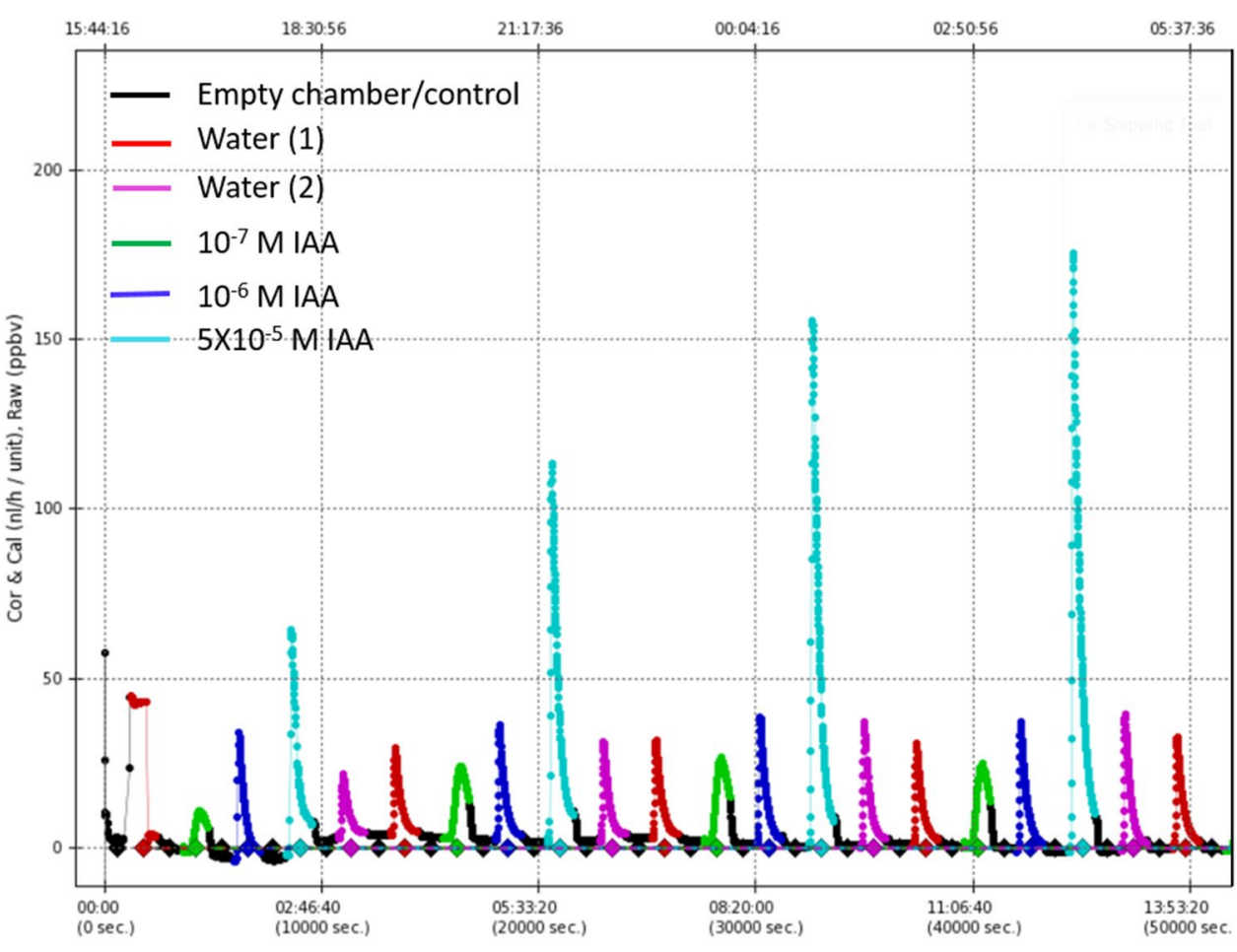


from the shoot part, transported within the central cylinder of the root and being reversed within the root tip to the outer epidermal tissues (Moore 2002). According to this model, in graviresponding roots, inhibition of growth of the lower organ flank is supposed to occur through a redistribution of auxin to the lower organ flank. Modern, methodically sophisticated molecular biological studies provided elegant and appealing evidence for this classic scenario (Friml et al. 2002; Ottenschläger et al. 2003a, b; Mellor et al. 2019; Brumos et al. 2018). They thereby apparently contributed to an additional consolidation, and an even more pronounced general acceptance - even if many intermediate steps in the molecular causal scenario remained open. Yet, the crucial question, namely the principle mechanism of inhibition of growth by IAA in root cells remained open. This, with respect to the aim of a coherent model, most crucial question, i.e. how does IAA inhibit cell elongation in roots, was not up for discussion: "it was a fact". Some of the early studies on IAA inhibition of root growth however indicated ethylene induced by IAA as the causal agent (Andreae et al. 1968; Wheeler and Salisbury 1981). Also, later studies, such as by Zhao and Hasenstein (2009), substantiate the impact of IAA on ethylene. They showed that silver thiosulfate, as an ethylene inhibitor, promotes root elongation, in addition to the enhancing effect of exogenous IAA on ACC oxidases, involved in ethylene synthesis. Nevertheless, this fact and its potential relevance for the mechanism of root growth regulation have not been followed-up. One can speculate about the reasons. Employing modern, molecular biological methods, impacts or cross-talk between ethylene and IAA and vice versa were reported within the last decades (Růžička et al 2007) - yet, still attributing IAA the cardinal role for developmental root growth inhibition. This role seems to be turning out to be wrong.

The finding reported here that the widely demonstrated auxin effect on root growth no longer exists as soon as the roots are not incubated directly in solution but are supplied via the shoot tissues but also the upper root parts with highly concentrated solutions of IAA sheds new light on the physiological causal scenario and casts strong doubts on the classical model.

Counter to this conclusion, it could be argued on the one hand that IAA as supplied from the shoot as well as the upper root part (Fig. 4) is discriminated and filtered out from the liquid on the way to the elongating root tip and does not get into the volume-increasing, expanding root cells. Such a scenario would not only render previous models of auxin transport obsolete but would overturn all models originating from IAA transportation investigations. Moreover, such an argument is also refuted by a simple physiological effect illustrated in the finding that roots of seedlings exposed to moist air exhibit pronounced lateral root formation, which are, under laboratory conditions within the analysed period, not observed in water controls (Fig. 6). Such IAA effects were demonstrated in previous studies (Casimiro et al 2001; Fukaki and Tasaka 2009). This distinct effect on lateral root formation as induced by shoot-originating IAA disproves such theoretical and unphysiological considerations. It confirms similar findings in various systems by other research groups, substantiating lateral root branching as a function of IAA (Thimann 1936; Casimiro et al. 2001) as well as of ethylene (Fukaki and Tasaka 2009). Since lateral root formation as triggered by ethylene has earlier been demonstrated, the reported dependency of lateral root formation on IAA may - nevertheless - also originate from IAA-triggered ethylene, and not of IAA, as such. It would represent a function of low levels of ethylene over longer times, yet, surprisingly, without any inhibiting effect on cell elongation of the air-exposed expanding primary root. Such a causal scenario is strongly supported by the results shown in Fig. 7, which clearly demonstrates the impact of shoot-originating IAA on root ethylene emission.

On the other hand, the previously unknown dependence of IAA inhibition of root growth on external physico-chemical conditions appears in accordance with a root growth regulatory scenario, which attributes ethylene the causative role for root growth inhibition - and not auxin — despite its dependence on auxin.

To comprehend such a model, one has to consider some physiological findings and physical facts.

Although the methods were comparatively not yet very precise, early studies demonstrated IAA-induced synthesis of ethylene (Kang et al. 1971). It was therefore suggested that auxin-inhibited root growth was mediated by ethylene (Andreae et al 1968; Chadwick and Burg 1970). In fact, Kang et al. (1971) demonstrated in shoots/internodes a strong concentration-dependent correlation between IAAmediated growth and, thereby, associated ethylene production in internode segments of Pisum sativum. The higher the exogenous IAA concentration, the stronger the increase in fresh weight and the extent of ethylene production. In accordance with and affirming their results, the present study demonstrates ethylene emission from roots induced by IAA applied from the kernel/shoot part of the seedling (Fig. 7). This finding clearly demonstrates the physiological impact of IAA within the root proper, apart from its effect on lateral root formation.

Looking at the circumstances and the physiological consequences of the classical methodological approach more specifically, a common feature of these studies consists in incubation of the roots in liquids. They analysed the impact of solutions of different concentrations of IAA and compared them with the ones observed in water-incubated roots — similar to the methodological approach underlying Fig. 1 in this study. By focussing on the effects of the applied hormone within the studied system, i.e. the thereby affected 
root metabolism, such methodical approaches apparently make sense. However, such treatments inevitably go along with effects dependent on external conditions, relevant for physiological processes within the examined system. In the presence of surrounding water, the gas diffusion conditions are quite different from those in air. As it seems, this physico-chemical effect of the surrounding water on the roots was previously either not noticed or just not considered/ ignored, despite its most important physiological, as well as ecophysiological relevance.

In addition to its low solubility in water, which enhances ethylene accumulation in the root tissue, it has long been demonstrated, which ethylene has, in water, a 10-thousand fold lower diffusion coefficient as compared to air (Abeles et al. 1992). As a consequence, IAA-induced ethylene (Fig. 7) will be retained in solution-incubated roots and thereby accumulate within the root proper, in contrast to air-exposed roots which emit ethylene to diffuse away into the surrounding air space. IAA-induced ethylene and its effect on cell elongation growth of the roots, therefore, also represent a function of the aggregate state of the root environment.

The findings reported here imply IAA-induced ethylene to be retained and accumulated up to concentrations sufficient for ethylene-mediated growth inhibition. It corroborates an earlier finding by Růžička et al. (2007) who suggested - besides or in addition to IAA-induced inhibition of root growth - ethylene-mediated inhibition of root cell elongation growth, yet without realising its ineffectiveness in air-exposed roots. These authors also showed "that the effect of ethylene on root growth is largely mediated by the regulation of the auxin biosynthesis and transport-dependent local auxin distribution"; in other words, an additional oneway focus is once again attributed to the direct inhibitory action of auxin on cell elongation. Evidence for a vice versa scenario is illustrated in Fig. 6: roots exposed to high IAA concentrations in solution are characterised by root swelling, both on the organ level as well as the cell level, which is not observed in IAA-supplied roots exposed to air, which release ethylene into the air space - with no effect on root elongation.

The briefly outlined scenario in roots would provide an explanation for the seemingly contradictory effects of IAA on shoot and root cell growth - mainly because it is IAA conducted, but ethylene executed. This discrimination, which could uncritically be dismissed as trivial, has profound and lasting consequences regarding the regulation of root development processes. It involves the physical environment of the root in the cell growth regulation process, via the diffusion conditions that have a retroactive effect on the root. Ethylene obviously exerts its effect on the root not only in dependence on surrounding water conditions, but also in dependence on soil compaction conditions, as has been shown in a recent paper (Pandey et al. 2021). The plant seems not only to be able to perceive mechanical impacts, but also to be able to sense the environment, or, metaphorically speaking, get a picture of its chemical and physical environment via the degree of retention of the emitted ethylene - as a function of different external diffusion conditions. It can therefore be assumed that similarly rhizobiome-borne volatile compounds may exert a root developmental impact, apart from, or in addition to, physical soil compaction conditions (Bonkowski et al. 2000).

This finding adds to the complex networking of auxin signalling reported earlier (Paciorek and Friml 2006). It highlights an additional, most relevant feature for the execution of endogenous signalling on the dependence of the external environment, which has not yet been considered in research on root development in dependence of auxin.

Very recent evidence for inhibition of root growth dependence on external conditions, as mediated by increased ethylene due to unfavourable diffusion conditions of rootborne ethylene, was recently also presented by Pandey et al. (2021). Their findings are in strong support of the here outlined regulation scenario of IAA-triggered, ethylenemediated inhibition of root growth in water. These authors speculate that ethylene accumulation within the root, due to soil compaction, induces "hormone responses that restrict growth" (Pandey et al. 2021). The results presented in this study, but also earlier studies (Weijers et al. 2018), strongly support inhibition of growth to be due to ethylene that inhibits growth above a certain threshold value.

As illustrated in Fig. 4, under conditions of air-exposed roots, neither elongation nor graviresponsive growth exhibits any dependence on the liquid by which roots are supplied from the shoot. Under these conditions, the only detectable difference between the two treatments, i.e. water supplied or IAA supplied, consists in the amount of emitted ethylene (Fig. 7), which obviously does not come into play because it can diffuse away. On the other hand, it has been demonstrated that gravitropic growth is gradually inhibited by increasing inhibition of ethylene synthesis (Edelmann and Roth 2006). Ethylene, and not auxin, therefore, seems to play a very subtle regulatory role in the mechanism of gravitropic growth regulation. Earlier studies (Edelmann et al. 2005) demonstrated exogenous ethylene to strongly enhance gravitropic growth of horizontally oriented maize roots, although by then its causal or regulatory positioning relative to auxin has not been recognised as illustrated in this study. Regarding the reiterated relevance of auxin in the previous graviregulation models, a crucial yet "dangerous feature" of this still fragmented model consists in its apparent plausibility: sedimentation of particles within a group of cells as an effect of gravity apparently "makes sense", and also the redistribution of an apparent growth-inhibiting hormone, namely 
auxin, apparently "makes sense". However, until now, there has no physiological process been reported causally connecting the one with the other.

The potentially intricate implications and manyfold consequences of the findings reported here for root development in general - but mainly the regulation of gravistimulated root growth - will be subject of a subsequent paper.

As recently outlined by Weijers et al. (2018), it is difficult to "describe any plant process without some direct or indirect reference to auxin". Auxin could therefore be the indispensable director, or conductor, who also orchestrates the ethylene that then inhibits root growth - i.e. not the "direct executor". The outcome as to whether the ethylene orchestrated by auxin comes into effect then depends on the external conditions.

With regard to a critically scrutinised, well-founded model of root growth regulation and its future exploration, the final causal addressee should not be auxin, but ethylene. That approach seems more likely to contribute to the concrete elucidation of the hitherto unsolved mechanisms of root growth regulation.

Acknowledgements I want to thank Robert Preiwuß and Florian Petrikat for careful and excellent technical assistance. Also, I would like to thank Dr Keith Baverstock, who has carefully proofread and corrected the manuscript for errors.

Funding Open Access funding enabled and organized by Projekt DEAL.

Open Access This article is licensed under a Creative Commons Attribution 4.0 International License, which permits use, sharing, adaptation, distribution and reproduction in any medium or format, as long as you give appropriate credit to the original author(s) and the source, provide a link to the Creative Commons licence, and indicate if changes were made. The images or other third party material in this article are included in the article's Creative Commons licence, unless indicated otherwise in a credit line to the material. If material is not included in the article's Creative Commons licence and your intended use is not permitted by statutory regulation or exceeds the permitted use, you will need to obtain permission directly from the copyright holder. To view a copy of this licence, visit http://creativecommons.org/licenses/by/4.0/.

\section{References}

Abeles FB, Morgan PW, Saltveit ME (1992) Ethylene in plant biology. Academic Press, San Diego

Alarcon MV, Lloret PG, Salguero J (2014) The development of the maize root system: role of auxin and ethylene. In: Morte A, Varma A (eds) Root engineering, Soil Biology 40. (C) Springer-Verlag Berlin Heidelberg. https://doi.org/10.1007/978-3-642-54276-3_5

Aloni R (2021) The hormonal signals that regulate plant vascular differentiation. In: Vascular differentiation and plant hormones. Springer, Cham. https://doi.org/10.1007/978-3-030-53202-4_3

Andreae WA, Venis MA, Jursic F, Dumas T (1968) Does ethylene mediate root growth inhibition by indole-3-acetic acid? Plant Physiol 43:1375-1379
Arsuffi G, Braybrook SA (2018) Acid growth: an ongoing trip. J Exp Bot 69(2):137-146. https://doi.org/10.1093/jxb/erx390

Bleeker AB Kende H (2000) Ethylene: a gaseous signal molecule in plants. Annu Rev Cell Dev Biol 16:1-18

Bonkowski M, Cheng W, Griffiths BS, Alphei J, Scheu S (2000) Microbial-faunal interactions in the rhizosphere and effects on plant growth. Eur J Soil Biol 36:135-147

Brumos J, Robles LM, Yun J, Vu TC, Jackson S, Alonso JM, Stepanova AM (2018) Local auxin biosynthesis is a key regulator of plant development. Dev Cell 47:306-318

Casimiro I, Marchant A, Bhalerao RP, Beeckman T, Dhooge S, Swarup R, Graham N, Inzé D, Sandberg G, Casero PJ, Bennett M (2001) Auxin transport promotes Arabidopsis lateral root initiation. Plant Cell 13:843-852. https://doi.org/10.1105/tpc.13.4.843

Chadwick AV, Burg SP (1967) An explanation of the inhibition of root growth caused by indole-3-acetic acid. Plant Physiol 42:415-420

Chadwick AV, Burg SP (1970) Regulation of root growth by auxinethylene interaction. Plant Physiol 45:192-200

Cleland RE (1970) Cell wall extension. Annu Rev Plant Physiol 22:197-222

Cline MG (1997) Concepts and terminology of apical dominance. Am J Bot 84(9):1064-1069

Cosgrove DJ (2000) Loosening of plant cell walls by expansins. Nature 407:321-326

Cosgrove DJ (2015) Plant expansins: diversity and interactions with plant cell walls. Curr Opin Plant Biol 25:162-172. https://doi.org/ 10.1016/j.pbi.2015.05.014

Darley CP, Forrester AM, McQueen-Mason SJ (2001) The molecular basis of plant cell wall extension. Plant Mol Biol 47:179-195. https://doi.org/10.1023/A:1010687600670

Davies PJ (1995) Plant hormones: physiology, biochemistry and molecular biology. Springer Netherlands, Kluwer Academic Publishers. https://doi.org/10.1007/978-94-011-0473-9

Dreyer J, Edelmann HG (2018) Root cap-mediated evaluation of soil resistance towards graviresponding roots of maize (Zea mays L.) and the relevance of ethylene. Ann Bot 22:791-800. https://doi. org/10.1093/aob/mcx209

Edelmann HG (2001) Lateral redistribution of auxin is not the means for gravitropic differential growth of coleoptiles: a new model. Physiol Plant 112:119-126

Edelmann H (2018) Graviperception in maize plants: is amyloplast sedimentation a red herring? Protoplasma 255:1877-1881

Edelmann H, Schopfer P (1989) Role of protein and RNA synthesis in the initiation of auxin-mediated growth in coleoptiles of Zea mays L. Planta 179:475-485

Edelmann H, Roth U (2006) Gravitropic plant growth regulation and ethylene: an unsought cardinal coordinate for a disused model. Protoplasma 229:183-191

Edelmann HB, Bergfeld R, Schopfer P (1989) Role of cell-wall biogenesis in the initiation of auxin-mediated growth in coleoptiles of Zea mays L. Planta 179:486-494

Edelmann HG, Bergfeld R, Schopfer P (1995) Effect of inhibition of protein glycosylation on auxin-induced growth and the occurrence of osmiophilic particles in maize (Zea maysL.) coleoptile. J Exp Bot 46:1745-1752

Edelmann HG, Sabovljevic A, Nijo G, Roth U (2005) The role of auxin and ethylene for gravitropic differential growth of coleoptiles and roots of rye- and maize seedlings. Adv Space Res 36:1167-1174

Edwards K, Scott TK (1977) Rapid-growth responses of corn root segments: effect of auxin on elongation. Planta 135:1-5

Eliasson L, Bertell G, Bolander E (1989) Inhibitory action of auxin on root elongation not mediated by ethylene. Plant Physiol 91(1):310-4

Evans ML, Cleland RE (2008) The action of auxin on plant cell elongation. Crit Rev Plant Sci 2(4):317-365. https://doi.org/10.1080/ 07352688509382200 
Evans ML, Mulkey TJ, Vesper MJ (1980) Auxin Action on proton influx in corn roots and its correlation with growth. Planta 148(510):512

Firn R, Digby J (1980) The establishment of tropic curvatures in plants. Ann Rev Plant Physiol 31:131-148

French A, Ubeda-Toma S, Holman TJ, Bennett MJ, Pridmore T (2009) High-throughput quantification of root growth using a novel image-analysis tool. Plant Physiol 150:1784-1795

Friml J, Wisniewska J, Benkova E, Mendgen K, Palme K (2002) Lateral relocation of auxin efflux regulator PIN3 mediates tropism in Arabidopsis. Nature 415:806-809

Fukaki H, Tasaka M (2009) Hormone interactions during lateral root formation. Plant Mol Biol 69:437-449

Gälweiler L, Guan C, Müller A, Wisman E, Mendgen K, Palme K (1998) Regulation of polar auxin transport by AtPIN1 in Arabidopsis vascular tissue. Science 282:2226-2230

Hager A, Menzel H, Kraus A (1971) Experiments and hypothesis concerning the primary action of auxin in elongation growth. Planta 100:47-75. https://doi.org/10.1007/BF00386886

Hager A, Debus G, Edel HG, Stransky H, Serrano R (1991) Auxin induces exocytosis and the rapid synthesis of a high-turnover pool of plasma-membrane H(+)-ATPase. Planta 185(4):527-537. https://doi.org/10.1007/BF00202963

Hahn A, Firn R, Edelmann HG (2006) Interacting signal transduction chains in gravity-stimulated maize roots. Signal Transduct 6:449-455

Jackson M (1985) (1985) Ethylene and responses of plants to soil waterlogging and submergence. Ann Rev Plant Physiol 36:145-174

Kang BG, Newcomb W, Burg SP (1971) Mechanism of auxin-induced ethylene production. Plant Physiol 47:504-509

Kebrom TH (2017) A growing stem inhibits bud outgrowth - the overlooked theory of apical dominance. Front Plant Sci. https://doi. org/10.3389/fpls.2017.01874

Kieffer M, Neve J, Kepinski S (2010) Defining auxin response contexts in plant development. Curr Opin Plant Biol 13(1):12-20

Kleine-Vehn J, Sauer M (2017) Plant hormones. Springer Verlag, ISBN 978-1-4939-6467-3; ISSN 1064-3745

Kögl F, Haagen-Smit AJ, Erxleben H (1934a) Über ein neues Auxin (Heteroauxin) aus Harn. 11. Mitteilung über pflanzliche Wachstumsstoffe. Z Physiol Chem 228:90-103

Kögl F, Haagen-Smit AJ, Erxleben H (1934b) Über den Einfluß der Auxine auf das Wurzelwachstum und über die chemische Natur des Auxins der Graskoleoptilen. 12. Mitteilung über pflanzliche Wachstumsstoffe. Biol Chem 228:1-2

Kundu KK, Audus AJ (1974) Root growth inhibitors from root cap and root meristem of Zea mays L. J Exp Bot 25:479-489

Kutschera U (2006) Acid growth and plant development. Science 311:952-953

Kutschera U, Schopfer P (1985) Evidence against the acid-growth theory of auxin action. Planta 163:483-493

Kutschera U, Khanna R (2020) Auxin action in developing maize coleoptiles: challenges and open questions. Plant Signal Behav 15. https://doi.org/10.1080/15592324.2020.1762327

Lee JS, Chang WK, Evans ML (1990) Effects of ethylene on the kinetics of curvature and auxin redistribution in gravistimulated roots of Zea mays. Plant Physiol 94:1770-1775

Lv B, Yan B, Tian H, Zhang X, Ding Z (2019) Local auxin biosynthesis mediates plant growth and development. TIPS 24:6-9

McQueen-Mason S, Durachko DM, Cosgrove DJ (1992) Two endogenous proteins that induce cell wall extension in plants. Plant Cell 4(11):1425-1433

Mellor NL, Voß U, Janes G, Bennett MB, Wells DM, Band LR (2019) Auxin fluxes through plasmodesmata modify root-tip auxin distribution. Development 147:1-12

Moore I (2002) Gravitropism: lateral thinking in auxin transport. Curr Biol 12:452-454
Nielsen N (1930) Untersuchungen über einen neuen Wachstumsregulierenden Stoff: Rhizopin. Jahrb Wiss Bot 73:125-191

Ottenschläger I, Wolff P, Wolverton C, Bhalerao RP, Sandberg G, Ishikawa H, Evans M, Palme K (2003a) Gravity-regulated differential auxin transport from columella to lateral root cap cells. Proc Natl Acad Sci 100(5):2987-2991. https://doi.org/10.1073/pnas.04379 36100

Ottenschläger O, Wolff P, Wolverton C, Bhalerao RP, Sandberg G, Ishikawa H, Evans M, Palme K (2003b) Gravity-regulated differential auxin transport from columella to lateral root cap cells. PNAS 100 (5) 2987-2991. https://doi.org/10.1073/pnas.0437936100

Overvoorde P, Fukaki H, Beeckman T (2010) Auxin control of root development. Cold Spring Harb Perspect Biol 2:a001537. https:// doi.org/10.1101/cshperspect.a001537

Paâl A (1919) Ueber phototropische Reizleitung. Jahrb F Wiss Bot 32:499-502

Paciorek T, Friml J (2006) Auxin signaling. J Cell Sci 119:1199-2120

Pandey BK, Huang G, Bhosale R, Hartman S, Sturrock CJ, Jose L, Martin OC, Karady M, Voesenek LACJ, Ljung K, Lynch JP, Brown KM, Whalley WR, Mooney SJ, Zhang D, Bennett MJ (2021) Plant roots sense soil compaction through restricted ethylene diffusion. Science 371(6526):276-280

Rayle DL, Cleland RE (1992) The acid growth theory of auxin-induced cell elongation is alive and well. Plant Physiol 99:1271-1274. https://doi.org/10.1104/pp.99.4.1271

Růžička K, Ljung K, Vanneste S, Podhorská R, Beeckman T, Friml J, Benkova E (2007) Ethylene regulates root growth through effects on auxin biosynthesis and transport-dependent auxin distribution. Plant Cell 19:2197-2212

Solano R, Ecker JR (1998) Ethylene gas: perception, signaling and response. Curr Opin Plant Biol 1(5):393-398

Srivastava LM (2002) Plant growth and development. Academic Press. ISBN 978-0-12-660570-9

Su SH, Gibbs NM, Jancewicz AL, Masson PH (2017) Molecular mechanism of root gravitropism. Curr Biol 27:964-972

Thimann KV (1935) On an analysis of the activity of two growth-promoting substances on plant tissues. Proc Kon Akad Wetenschap Amsterdam 38:896-912

Thimann KV (1936) Auxins and the growth of roots. Am J Bot 23:561-569

Thimann KV (1969) The auxins. In: Wilkins MB (ed) The physiology of plant growth and development. McGraw-Hill, London, p 345

Weijers D, Nemhauser J, Yang Z (2018) Auxin: a small molecule, big impact. J Exp Bot 69:133-136

Went FW (1926) On growth-accelerating substances in the coleoptile of Avena sativa. Proc Sect Sci Koninklijke Akademie van Wetenschappen te Amsterdam 30:10-19

Went FW, Thimann KV (1937) Phytohormones. Macmillan, New York Wheeler RM, Salisbury FB (1981) Gravitropism in plant stems may require ethylene. Science 209:1126-1127

Woods L, Roberts JA, Taylor IB (1984) Ethylene-induced root coiling in tomato seedlings. Plant Growth Regul 2:217-225

Young ML, Evans ML, Hertel R (1990) Correlations between gravitropic curvature and auxin movement across gravistimulated roots of Zea mays. Plant Physiol 92:92-96

Zhao Y, Hasenstein KH (2009) Primary root growth regulation: the role of auxin and ethylene antagonists. J Plant Growth Regul 28:309-320

Publisher's note Springer Nature remains neutral with regard to jurisdictional claims in published maps and institutional affiliations. 